\title{
Health-Related Quality of Life in Children with Sickle Cell Disease: A Report from the Comprehensive Sickle Cell Centers Clinical Trial Consortium
}

\author{
Carlton Dampier, MD¹, Susan Lieff, $\mathrm{PhD}^{2}$, Petra LeBeau, $\mathrm{ScD}^{2}$, Seungshin $\mathrm{Rhee}^{2}$, Marsha \\ McMurray ${ }^{2}$, Zora Rogers, MD $^{3}$, Kim Smith-Whitley, MD $^{4}$, and Winfred Wang, MD $^{5}$ the \\ Comprehensive Sickle Cell Centers (CSCC) Clinical Trial Consortium (CTC) Site \\ Investigators \\ ${ }^{1}$ Department of Pediatrics, Emory University School of Medicine, Atlanta, GA \\ ${ }^{2}$ CSCC CTC Statistical Data Management Center, Rho Federal Systems Division, Rho, Inc., \\ Chapel Hill, NC \\ ${ }^{3}$ University of Texas Southwestern, Dallas, TX \\ ${ }^{4}$ The Children's Hospital of Philadelphia, Philadelphia, PA \\ ${ }^{5}$ St. Jude Children's Research Hospital, Memphis, TN
}

\begin{abstract}
Background-Pediatric health-related quality of life (HRQOL) questionnaires have been validated in children with sickle cell disease (SCD), but small sample sizes in these studies have limited clinical comparisons. We used the baseline clinical data from the Collaborative Data (CData) Project of the Comprehensive Sickle Cell Centers (CSCC) Clinical Trial Consortium to perform a detailed, descriptive study of HRQOL using the PedsQL ${ }^{\mathrm{TM}}$ version 4.0 generic core and fatigue scales.
\end{abstract}

\begin{abstract}
Methods-Retrospective clinical data were obtained via medical record abstraction. Staffadministered health history, psychosocial, and health behavior interviews were completed by a parent or guardian. PedsQL ${ }^{\mathrm{TM}}$ forms were completed separately by the child and a parent/ guardian.
\end{abstract}

\begin{abstract}
Results-The study enrolled 1772 subjects (53\% boys) with a mean age of 9.6 years (SD 4.7). $\mathrm{SS}$ or $\mathrm{S} \beta^{0}$ thalassemia occurred in $68 \%$ and $32 \%$ had SC or $\mathrm{S} \beta^{+}$thalassemia. The occurrences of pain, priapism, avascular necrosis of hips/shoulders (AVN), or asthma were the most common complications/conditions reported. Multiple regression models controlling for hemoglobinopathies, gender, and age suggested that parent reports of physical functioning and sleep/rest fatigue declined in response to pain or AVN, while school functioning scales declined in response to pain or asthma. Sickle pain, and to a lesser extent asthma, negatively influenced child reports on almost all functioning and fatigue scales.
\end{abstract}

Conclusions-While longitudinal studies will be necessary to determine sensitivity to change, the current study suggests the potential utility of several PedsQL ${ }^{\mathrm{TM}}$ HRQOL scales as patientreported outcome measures for observational or interventional treatment studies of children and adolescents with SCD.

Correspondence: Carlton Dampier MD, Office for Clinical Research, Emory University School of Medicine, Mailstop 1599-006, 1599 Clifton Rd NE, Atlanta, GA 30322, phone: 404.778.2561, fax: 404.778.4989, cdampie@ emory.edu. 


\section{Keywords}

HRQOL; Sickle Cell Disease; Peds QL

\section{INTRODUCTION}

Occasional episodic acute complications characterize sickle cell disease (SCD) in childhood. These acute complications often become more frequent in adolescents, who additionally begin to display variable degrees of chronic multi-organ dysfunction typical of adults with this disorder. Pain resulting from sickle erythrocyte vaso-occlusion is the most common acute complication in children, with both pain and priapism potentially becoming frequently recurrent complications. Avascular necrosis of hips or shoulder joints, and cardiopulmonary or renal dysfunction are examples of chronic complications that become increasingly prevalent in adolescents and young adults [1,2].

These acute and chronic complications lead to predictable disease-related symptoms. For example, hemolysis causes variable degrees of chronic anemia that contributes to fatigue and activity limitations, and vaso-occlusion associated with sickled erythrocytes causes acute and chronic pain [3]. Studies of vaso-occlusive pain episodes using self-report pain diaries [4-6] have provided descriptions of the effects of these acute complications on affected individuals from their own perspective. Health-related quality of life (HRQOL) measures are increasingly being used in both descriptive and interventional studies to obtain similar self-report information on a range of domains $[7,8]$ in a wide variety of disorders, allowing comparisons across age groups, functional limitations, or symptoms $[9,10]$.

Health-related quality of life questionnaires have been used in several pediatric SCD studies [11-15], which have provided preliminary evidence for validity and reliability. In these studies, caregivers of children with SCD reported that their children had more limited physical, psychological, and social well-being than healthy children. Compared with their children's reports, parents reported worse HRQOL in the overall perception of their children's health, physical functioning, behavior, and self esteem. Older child age, female gender, lower income, and more severe disease were correlated with greater limitations in the physical health of children with SCD.

The large SCD population participating in studies conducted by the Comprehensive Sickle Cell Centers (CSCC) Clinical Trial Consortium (CTC) provided an opportunity to further describe the responses of 1700 parents/guardians and their children using the Pediatric Quality of Life Inventory (PedsQL ${ }^{\mathrm{TM}}$ ) and to examine the relationship between domains of reported HRQOL in SCD and various disease-related complications.

\section{Background}

The 2003 National Heart Lung and Blood Institute (NHLBI) Request for Applications (RFA) scope of work for the CSCC Program required the development of a database to capture information on patients receiving care at the CSCC Centers. The Collaborative Data (C-Data) Project, a large multi-faceted database effort, was designed to meet this requirement. The objectives of the database included: 1) development of a resource for use in planning future multi-center studies in SCD;2) formulation of standard definitions for the most common clinical complications of SCD; 3) assessment of the social and financial burden of living with this disease; and 4) collection of information relevant to the daily quality of life of individuals with SCD. The investigation and analysis of HRQOL among children with SCD described in this paper represents one component of the C-Data Project. 
At the onset of the C-Data project, validated instruments specifically designed to assess HRQOL for adult or pediatric sickle cell populations were not available. The protocol team reviewed several standardized HRQOL and subject satisfaction instruments to determine the most appropriate for use in the pediatric SCD population. The availability of separate core modules for parents and children and of age-appropriate versions, the potential for independent and combined assessment of the domains, and the widespread experience with its use in other chronic disease populations were factors considered in selecting the PedsQL ${ }^{\mathrm{TM}}$ as the C-Data HRQOL instrument.

\section{MATERIALS AND METHODS}

At the time of initial enrollment, study staff administered psychosocial and health behavior interviews that required approximately 10 minutes to complete. Two versions of the interview were utilized: one for children accompanied by a parent/guardian and one for participants answering independently. The PedsQL ${ }^{\mathrm{TM}}$ was self-administered as described below. Retrospective clinical data on medical conditions, SCD complications, surgeries, medications, procedures, and medical tests were obtained by medical record abstraction.

\section{Study Population, Recruitment, and Enrollment}

Adult and pediatric patients with all forms of SCD at participating CSCC Centers and satellite sites were considered eligible for C-Data Project enrollment if seen within the last 24 months and were expected to return for care. Participant enrollment occurred either at the time of a special C-Data recruitment event or at a routine clinic visit. Nine CSCC centers, representing 19 clinical sites, participated in the C-Data Project.

Completion of informed consent, the enrollment form, interview, collection of clinical data, and age-appropriate HRQOL modules was required in order to consider an individual's baseline data complete. Only those participants with complete baseline data were included in the analysis for this manuscript.

\section{Measurement}

The detailed guidelines and interview script for administration, and recommended scoring for each module, including methods for handling missing data and forms, provided with the leasing agreement for the PedsQL ${ }^{\mathrm{TM}}$ instruments were used without modification in the conduct of this study. In this study, the HRQOL forms were self-administered for parents and children ages 8 to 18 and interviewer-administered for children ages 5 to 7 . Parents and children were required to complete the questionnaires independently. Children with documented developmental delay used the HRQOL form reflective of their developmental age. Parents and children with limited literacy had the questions read to them. If a language barrier was present, HRQOL measurements were not obtained as validated non-English versions were not available at the time the study was initiated.

\section{The PedsQL ${ }^{T M}$ Generic Core Scale}

The PedsQL ${ }^{\text {TM }}$ version 4.0 [16] is a multi-dimensional child self-report and parent proxy report of generic core measures integrated with disease-specific modules. The PedsQL ${ }^{\mathrm{TM}}$ Generic Core has four domains: physical, emotional, social and school functioning, with child self-report versions for a broad age range (age groups 5-7, 8-12, and 13-18) and parallel parent proxy reports for each age group. The PedsQL ${ }^{\text {TM }}$ includes only a parent proxy report for toddlers age $2-4$. Likert response scale items are reverse-scored and linearly transformed to a $0-100$ scale $(0=100,1=75,2=50,3=25,4=0)$, so that higher PedsQL ${ }^{\text {TM }}$ scores indicate better HRQOL. Substantial normative data from a wide range of pediatric disorders are available [16-20]. 


\section{The PedsQLTM Multidimensional Fatigue Scale}

The 18-item PedsQL ${ }^{\mathrm{TM}}$ Multidimensional Fatigue Scale is composed of 3 subscales: General Fatigue (6 items), Sleep/Rest Fatigue (6 items), and Cognitive Fatigue (6 items). This scale has parallel child self-report and parent proxy-report formats identical to those of the Generic Core Scales. The format, instructions, and scoring method are also identical to the Generic Core Scales.

\section{Presence of Medical Conditions, Disease Complications, and Co-morbid Conditions}

A physician diagnosis of asthma, a previous radiographic diagnosis of avascular necrosis of hips or shoulders (AVN) or previous occurrence of priapism were determined from structured review of available medical records. These disease complications/medical conditions or co-morbid conditions (asthma) were the only ones with sufficient prevalence in this pediatric SCD population for subsequent analysis. The number of acute care visits for pain in the preceding year and the number of days of work/school missed due to pain in the preceding year were obtained from parent/patient report.

\section{Statistical Methods}

Statistical analyses for this manuscript were generated using SAS/STAT ${ }^{\circledR}$ software, Version 9.1 of the SAS System for Windows [21]. Data were analyzed for the total sample and separately by age group. The distribution of the scale scores was evaluated by the percentage of lowest possible scores (floor) and highest possible scores (ceiling) by age group. Internal reliability was assessed by calculating Cronbach's coefficient alpha [22], with a value of 0.7 or greater judged to be acceptable reliability. In order to assess the agreement between parent report and child report, Pearson correlation coefficients and intraclass correlation coefficients (ICC) using a two-way mixed model were calculated. General linear models controlling for gender, sickle hemoglobinopathy type, and age group were used to examine relationships between scale scores and the number of missed school or work days due to sickle cell pain, or the number of acute care visits for sickle cell pain, and the presence of AVN, priapism, or asthma. For the purposes of reporting, a p value of 0.05 was used as a measure of descriptive statistical significance. $P$ values were not adjusted for multiple comparisons, so results should be considered exploratory.

\section{RESULTS}

The average age of the 825 girls (47\%) and 947 boys (53\%) was 9.6 years (standard deviation [SD] 4.7, median 9) with a range of 2 to 18 years. For child self-report, the average age of the 639 girls (46\%) and the 754 boys (54\%) was 11.3 years (SD 3.8 median 11) with a range of 5 to 18 years. As expected, the participants were largely Black or African-American (95\%) of non-Hispanic/Latino ethnicity (95\%) (Table I). The sample included 1210 children with SS or S $\beta^{0}$ thalassemia (68\%) and 562 children with SC or S $\beta^{+}$ thalassemia (32\%). Table I also shows the distribution of hemoglobin levels, SCD complications and associated conditions, days hospitalized, and days missed from school/ work in this sample.

\section{Distribution of scores}

The number of non-missing observations, mean and standard deviation of the scale scores, and the percent at floor and ceiling responses are presented in Table II. No significant floor effects $(\leq 1 \%)$ were seen on either parent or child report, but moderate ceiling effects (15$30 \%$ ) were observed in some scales, such as social or emotional functioning and cognitive fatigue (parent and child report) and general and sleep/rest fatigue scales (parent report). Ceiling effects were most prominent in the youngest age group, with 6 of 9 scales of the 
parent report for the 2-4 age group having more than $30 \%$ scoring at the maximum. Since the relatively large ceiling effect for this age group caused a left-skewed distribution, the 24 age group was excluded in subsequent analyses.

\section{Internal consistency - Cronbach alpha}

Cronbach alpha scores were greater than 0.7 for all parent and child report scales except for school functioning (child report), which was 0.69. Parent reports had higher Cronbach alpha values, ranging between 0.79 and 0.95 , than did child reports, which ranged between 0.69 and 0.88 .

\section{Parent-Child Correlations}

Pearson correlations for the relationship between parent and child reports showed moderate correlations ranging from 0.38 to 0.47 . Overall, the 5-7 year old age group had lower correlation coefficients between child and parent reports (range 0.26-0.39) than either the older child (range 0.38-0.49) or teen age groups (range 0.48-0.55). As expected, less easily observed items (e.g., those related to social and emotional functioning) showed somewhat lower parent-child correlations for all age groups.

\section{Clinical Relationships}

The PedsQL ${ }^{\mathrm{TM}}$ scales were evaluated by ANOVA, without controlling for any other covariates, to explore relationships between groups likely differing in clinically relevant variables (age group, gender, hemoglobinopathy type, and hospitalization frequency) as the study design was cross-sectional in nature. There was a progressive decline in all parentreported PedsQL ${ }^{\mathrm{TM}}$ scale scores except for cognitive fatigue across younger to older age groups (5-7, 8-12, 13-18), reflecting a declining health-related quality of life (Figure 1A, Supplemental Table I). Overall tests of mean difference across age groups were statistically significant for parent-reported total $(\mathrm{p}<0.001)$, physical $(\mathrm{p}=0.002)$, emotional $(\mathrm{p}=0.027)$, school functioning $(\mathrm{p}<0.001)$, total, general, sleep/rest fatigue scales (all $\mathrm{p}<0.001)$, and cognitive fatigue scale $(\mathrm{p}=0.01)$, as well as for child-reported physical $(\mathrm{p}=0.023)$, emotional $(\mathrm{p}=0.002)$, social $(\mathrm{p}<0.001)$, school functioning $(\mathrm{p}=0.007)$, and sleep/rest $(\mathrm{p}=0.014)$ and cognitive fatigue $(\mathrm{p}=0.002)$ scales. Mean PedsQL $\mathrm{L}^{\mathrm{TM}}$ scale scores from child reports were somewhat higher than parent reports and were variable across age groups, but were much lower than those of a population of age-matched healthy children (Figure 1B).

Female gender was associated with statistically significantly but nominally lower scores in parent-reported physical functioning $(\mathrm{p}=0.009)$ and sleep/rest fatigue scales $(\mathrm{p}=0.01)$. Similar gender differences were noted for child-reported total $(\mathrm{p}<0.001)$, physical $(\mathrm{p}<0.001)$, emotional functioning $(\mathrm{p}=0.003)$, and total $(\mathrm{p}=0.006)$, general $(\mathrm{p}=0.021)$, sleep/rest $(\mathrm{p}=0.036)$, and cognitive fatigue $(\mathrm{p}=0.019)$ scales (Supplemental Table I).

Between hemoglobinopathy phenotype groups, there were modest but statistically significant higher parent-reported scale scores for the $\mathrm{SC} / \mathrm{S} \beta^{+}$thalassemia group than the SS/ $\mathrm{S} \beta^{0}$ thalassemia group in total $(\mathrm{p}=0.008)$, physical $(\mathrm{p}=0.007)$, social $(\mathrm{p}=0.003)$, and school functioning $(\mathrm{p}=0.003)$, and general fatigue scores $(\mathrm{p}=0.033)$, as well as for child-reported total $(\mathrm{p}=0.022)$, physical $(\mathrm{p}=0.002)$, and social functioning $(\mathrm{p}=0.024)$ (Figure 2, Supplemental Table I).

Similar to age-related changes in scale scores, there was a decline in all parent and childreported scale scores for groups with 1-3 or $\geq 4$ hospitalizations compared to those with no hospitalizations in the previous 2 years (Figure 3 ). Statistically significant mean differences across hospitalization groups were observed for parent-reported functioning and fatigue scales (all $\mathrm{p}<0.001$, except cognitive fatigue $\mathrm{p}=0.024$ ), and child-reported functioning scales 
(all $\mathrm{p}<0.001$, except social functioning), and total $(\mathrm{p}=0.028)$ and general $(\mathrm{p}<0.001)$ fatigue scales.

The effects of occurrence of vaso-occlusive pain (the occurrence of any acute care visit for pain in the preceding year), the occurrence of most prevalent other recurrent or chronic complications (AVN, priapism), and the occurrence of associated conditions (asthma) on each of the scale scores, were compared together as covariates in multiple regression models controlling for gender, age group, and hemoglobinopathy group. Regression coefficients were compared to estimate the impact of these covariates on scale scores. Hemoglobin levels were not significant in regression models when hemoglobinopathy groups were also included. Use of occurrence of hospitalizations as a covariate in regression models provided similar results to that of the occurrence of pain-related acute care visits, but the later covariate was used in models as it was a more specific measure of pain. The occurrence of acute care visits for sickle pain was the dominant covariate negatively influencing all Peds QL scale scores for both parent-proxy and child reports (Table III, all $\mathrm{p}<0.001$ except child report for cognitive fatigue $(\mathrm{p}=0.004))$. An additional significant negative effect of a previous radiologic diagnosis of AVN compared to those without AVN was observed on parent reports for total $(\mathrm{p}=0.025)$, physical $(\mathrm{p}=0.006)$, and emotional $(\mathrm{p}=0.042)$ functioning, and sleep/rest fatigue scales $(\mathrm{p}=0.006)$ (Table III). Similarly, an additional significant negative impact of a previous physician diagnosis of asthma was noted for all parent reports for functioning and fatigue scales $(\mathrm{p} \leq 0.002)$, except sleep/rest fatigue, and for child reports for total $(\mathrm{p}=0.005)$, social $(\mathrm{p}=0.017)$, and school functioning $(\mathrm{p}<0.001)$, as well as the general fatigue scale $(\mathrm{p}=0.003)$ (Table III). A previous episode of priapism had a relatively modest effect, with a significant additional negative effect observed for only parent reports for total $(\mathrm{p}=0.038)$ and school functioning scales $(\mathrm{p}=0.025)$, and for general fatigue scale $(\mathrm{p}=0.048)$.

In separate linear regression models including either missed days by child or parent as covariates, controlling for age group, gender, and hemoglobinopathy group, all parent- and child-reported scores for functioning and fatigue scales (all, $\mathrm{p}<0.001$ ), except child-reported cognitive fatigue, showed a statistically significant negative relationship with the number of days missed from school by the SCD child or work by the primary caregiver, with parentreported school functioning being the most negative (Table IV).

\section{DISCUSSION}

The availability of a database with well-validated clinical data on a large, geographically diverse, pediatric SCD population provided a unique opportunity to further describe child and parent reports of health-related quality of life. The psychometric properties (percentage of floor/ceiling effects, internal consistency, confirmatory factor analysis) of the PedsQL ${ }^{\mathrm{TM}}$ questionnaire when administered to this large SCD population were similar to those previously reported in a much smaller single institution study [15], and in larger general pediatric populations $[10,16]$. In general, studies with the PedsQL ${ }^{\mathrm{TM}}[8-10,15-20]$ have shown adequate validity and reliability, but with some reduction in internal consistency and larger ceiling effects in the younger age groups. Similarly in this study, most scale ranges had a low percentage of responses in the most severe categories (floor effects), but had modest percentages of responses in the least severe categories (ceiling effects), particularly in the youngest age group (2-4 year old), child/parent reports on the social or emotional functioning scales, and for parent reports on the fatigue scales (Table II). Potential causes include item or response wording, relative difficulty of items within scales, and difficulties with parent proxy report on behaviors not easily observed, such as those in school. Scales with reduced ceiling effects would potentially have shown a broadening in scale scores 
toward improved quality of life and a somewhat larger variance of scale scores, which might have reduced the statistical significance shown in this study.

The type of hemoglobinopathy was the most relevant clinical grouping for comparisons of PedsQL ${ }^{\text {TM }}$ scores. A dichotomous phenotype grouping $\left(\mathrm{SS} / \mathrm{S} \beta^{0}\right.$ thalassemia versus $\mathrm{SC} / \mathrm{S} \beta^{+}$ thalassemia) was used in analyses as the frequencies of the doubly heterozygous conditions are relatively low. The first two disorders, at least in children, are generally considered to be more severe with more frequent complications and more severe anemia, whereas the latter two disorders have less frequent complications and less severe anemia. In contrast to previous smaller, single-institution studies [11-15], this study showed statistically significant diminished child- and parent-reported HRQOL, particularly in physical and social functioning, for children and adolescents with $\mathrm{SS} / \mathrm{S} \beta^{0}$ thalassemia compared to those with $\mathrm{SC} / \mathrm{S} \beta^{+}$thalassemia. However, the magnitude of these differences are smaller than those generally considered to be clinically significant [16], consistent with the considerable overlap in symptomatology between hemoglobinopathy diagnoses during childhood.

Other clinically relevant groupings include age and gender, as age-related increases in frequency and prevalence of acute and chronic complications are well recognized [24-26], and gender differences in pain frequency have been described [24]. The large sample size of this study allowed documentation of progressive age-related decreases in virtually all parentreported and most child-reported functioning and fatigue scale scores. A previous study using the Child Health Questionnaire reported similar results for the parent-reported physical functioning summary score [12]. While children reported statistically significant gender differences in HRQOL with diminished scores on most functioning scales for female subjects, these modest differences are not likely to be clinically significant [16].

The occurrence of acute and chronic complications requiring subsequent medical management was expected to have a negative impact on HRQOL. In this pediatric SCD population, the most frequent SCD-related complications were the occurrence of vasoocclusive pain or priapism, and the presence of AVN of one or both shoulders/hips. A previous physician diagnosis of asthma was the most common associated condition to SCD in this sample. Within the limitations of their sample sizes, several previous studies have reported diminished parent-reported physical functioning in children with severe compared to mild disease, categorized by a variety of composite severity scores [12-15]. The occurrence of an acute care visit for pain treatment in the preceding year was used as an example of a SCD acute complication and was associated with substantially diminished scores on virtually all parent- and child-reported scales of the PedsQL ${ }^{\mathrm{TM}}$, with physical and school functioning and general fatigue scales showing the most prominent decrements. Prominent effects on both parent-reported physical functioning and sleep/rest fatigue scales were observed for children with a current or previous diagnosis of AVN, and on most parent-reported school functioning for those children with a previous history of priapism.

Inclusion of these complications and associated conditions in the same general linear regression model controlling for age group, gender, and hemoglobinopathy group allowed us to determine the relative importance of each on scale scores. These models suggest that the occurrence of sickle pain or AVN most impacted parent reports of physical functioning and sleep/rest fatigue, while the occurrence of sickle pain or asthma most impacted school functioning. Similarly, the occurrence of sickle pain, and to a lesser extent asthma, negatively influenced child reports on almost all functioning and fatigue scales. The cooccurrence of these complications would be expected to significantly impair health-related quality of life. 
Parent-reported days of work missed or child absences from school were viewed as potential composite measures of disease activity and healthcare visits that were likely to impact parent- or child-reported quality of life. Parent- and child-reported HRQOL were progressively diminished with increasing frequency of both of these potential measures of disease activity similar to that of the frequency of individual disease complications. The parent-reported school days missed in the previous year were similar to previous reports of absenteeism for school-aged SCD children that verified data from school records [27,28].

There are several limitations to this study. Many clinical sites within the CSCC CTC did not have comprehensive patient databases that would have allowed a random sampling strategy, or accurate estimations of the percentage of the clinical population that enrolled in the study. In the absence of surveillance data on large geographic SCD populations, it is difficult to ascertain whether the clinical complications noted in the study participants are more frequent or less frequent than expected. The study teams at each clinical site extensively validated clinical data from available medical records, which were generally available for this pediatric population. However, some self-report information including days missed from work or school were not independently verified and thus may be less accurate.

\section{Conclusion}

Using a large, geographically diverse pediatric SCD population from the Comprehensive Sickle Cell Centers Clinical Trial Consortium, we have provided a detailed description of parent proxy and child reports of their HRQOL using the PedsQL ${ }^{\mathrm{TM}}$ questionnaire in relationship to carefully verified clinical data. In a cross-sectional design, several functioning and fatigue scales were sensitive to important clinically relevant differences in age, occurrence of vaso-occlusive pain or AVN, and the occurrence of asthma. Longitudinal studies in randomly selected SCD subjects will be necessary for further validations, particularly for determinations of sensitivity to change, but our study suggests the potential usefulness of certain HRQOL scales as patient-reported outcome measures for observational or interventional studies of children and adolescents with SCD. Refinement and calibration of similar items in children with a variety of chronic diseases, including sickle cell disease, is currently being conducted by the National Institutes of Health's Patient-Reported Outcomes Measurement Information System (PROMIS) Network, potentially providing optimized assessment tools for future pediatric SCD studies.

\section{Supplementary Material}

Refer to Web version on PubMed Central for supplementary material.

\section{Acknowledgments}

NIH Support The Collaborative Data Project was supported by the National Heart Lung and Blood Institute, Award Number U54HL070587. The content is solely the responsibility of the authors and does not necessarily represent the official views of the NHLBI or the National Institutes of Health. Dr. Greg Evans was the NHLBI Project Officer for this effort.

Protocol Team The C-Data Protocol Team included: Susan Lieff, PhD; Karen Kesler, PhD; Zora Rogers, MD; Carlton Dampier, MD; Winfred Wang, MD; Cage Johnson, MD; George Buchanan, MD; Kwaku Ohene-Frempong, MD; Samir Ballas, MD; and Matthew Heeney, MD.

Statistical and Data Coordinating Center Rho Federal Systems of Rho, Inc. provided the leadership for the planning and organizational support for this study including protocol development and the full range of clinical, epidemiologic, data management, and statistical activities. Collaborating Institutions The Collaborative Data Project was a collaboration of the following institutions, investigators, and study coordinators (site principal investigators are indicated by asterisks:Boston Medical Center, Boston, MA-Lillian McMahon, MD*, Asif Qureshi, Shafat Quadri; Children's Hospital of Boston, Dana-Farber Cancer Institute, Boston, MA-Matthew Heeney, MD*, Tiffany Kang, Amber Smith; Brigham and Women's Hospital, Boston, MA—Maureen Okam, 
MD*, Ainsley Ross, Carole Tremonti; Montefiore Medical Center, Albert Einstein College of Medicine, Bronx, NY-Lennette Benjamin, MD*, Gwendolyn Swinson, Arlette Paul; Children's Hospital at Montefiore, Bronx, NY -Catherine Driscoll, MD*; The Children's Hospital of Philadelphia, Philadelphia, PA-Kim Smith-Whitley, MD*, Henrietta Enninful-Eghan, Tannoa Jackson; Cincinnati Children's Hospital Medical Center, Cincinnati, OH - Karen Kalinyak, MD*, Tammy Nordheim, Marlene Eaton; Duke University Medical Center, Durham, NCLaura DeCastro, MD*, Michael Armstrong, MD*, Jude Jonassaint, Christle Cameron, Amanda Mandy; University of North Carolina, Chapel Hill, NC-Kenneth Ataga, MD*, Ruth Baldwin, Perrior Anderson; Drexel University College of Medicine, St. Christopher's Hospital for Children, Philadelphia, PA—Carlton Dampier, MD*, Camille Coleman; Cardeza Foundation for Hematologic Research, Thomas Jefferson University, Philadelphia, PA-Samir Ballas, MD*, April Deoria, Carol Wexler; University of Louisville, Louisville, KY—Ashok Raj, MD*, Salvatore Bertolone, MD, Claudia Grandinetti; Children's Hospital and Research Center Oakland, Oakland, CA-Elliott Vichinsky, MD*, Christine Hoehner, Susan Paulukonis; University of Miami, Miami, FL—Ofelia Alvarez, MD*, Patricia Williams, Mary Donovan; University of California, San Francisco, San Francisco, CA—James Huang, MD*, Laura Quill, Jonah Todd-Geddes; St. Jude Children's Research Hospital, Memphis, TN—Winfred Wang, MD*, Karen Winton, Lynn Wynn; University of Texas Southwestern, Dallas, TX-Zora Rogers, MD*, Cynthia Rutherford, MD*, Leah Adix, Nancy Lee; University of Oklahoma Health Sciences, Oklahoma City, OK-Joan Parkhurst Cain, MD*, Christina Gonzalez, Annette Johnson; University of Texas Medical Branch, Galveston, TXDavid Bessman, MD*, Lisa Hernandez Garcia, Phyllis Crawford.

\section{References}

1. Chiang EY, Frenette PS. Sickle cell vaso-occlusion. Hematol Oncol Clin North Am. 2005; 19:771784. [PubMed: 16214643]

2. Castro O, Gladwin MT. Pulmonary hypertension in sickle cell disease: mechanisms, diagnosis, and management. Hematol Oncol Clin North Am. 2005; 19:881-896. [PubMed: 16214649]

3. Kato GJ, Gladwin MT, Steinberg MH. Deconstructing sickle cell disease: Reappraisal of the role of hemolysis in the development of clinical subphenotypes. Blood Rev. 2007; 21:37-47. [PubMed: 17084951]

4. Shapiro BS, Dinges DF, Orne EC, et al. Home management of sickle cell-related pain in children and adolescents: natural history and impact on school attendance. Pain. 1995; 61:139-144. [PubMed: 7644237]

5. Dampier C, Ely B, Brodecki D, O'Neal P. Characteristics of pain managed at home in children and adolescents with sickle cell disease by using diary self-reports. J Pain. 2002; 3:461-470. [PubMed: 14622732]

6. Dampier C, Ely E, Brodecki D, O'Neal P. Home management of pain in sickle cell disease: A daily diary study in children and adolescents. J Pediatr Hematol Oncol. 2002; 24:643-647. [PubMed: 12439036]

7. Brandow AM, Brousseau DC, Panepinto JA. Postdischarge pain, functional limitations and impact on caregivers of children with sickle cell disease treated for painful events. Br J Haematol. 2009; 144:782-788. [PubMed: 19055663]

8. Varni JW, Burwinkle TM, Katz ER. The PedsQL TM in pediatric cancer pain: A prospective longitudinal analysis of pain and emotional distress. J Dev Behav Pediatr. 2004; 25:239-246. [PubMed: 15308924]

9. Varni JW, Limbers CA, Burwinkle TM. Impaired health-related quality of life in children and adolescents with chronic conditions: A comparative analysis of 10 disease clusters and 33 disease categories/severities utilizing the PedsQL TM 4.0 Generic Core Scales. Health Qual Life Outcomes. 2007; 5:43-58. [PubMed: 17634123]

10. Varni JW, Limbers CA, Burwinkle TM. Parent proxy-report of their children's health-related quality of life: An analysis of 13,878 parents' reliability and validity across age subgroups using the PedsQL ${ }^{\text {TM }}$ 4.0 Generic Core Scales. Health Qual Life Outcomes. 2007; 5:2-12. [PubMed: 17201923]

11. Palermo TM, Schwartz L, Drotar D, McGowan K. Parental report of health-related quality of life in children with sickle cell disease. J Behav Med. 2002; 25:269-283. [PubMed: 12055777]

12. Panepinto JA, O'Mahar KM, DeBaun MR, et al. Validity of the child health questionnaire for use in children with sickle cell disease. J Pediatr Hematol Oncol. 2004; 26:574-578. [PubMed: 15342984] 
13. Panepinto JA, O’Mahar KM, DeBaun MR, et al. Health-related quality of life in children with sickle cell disease: Child and parent perception. Br J Haematol. 2005; 130:437-444. [PubMed: 16042695]

14. McClellan CB, Schatz J, Sanchez C, Roberts CW. Validity of the Pediatric Quality Of Life Inventory for youth with sickle cell disease. J Pediatr Psychol. 2008; 33:1153-1162. [PubMed: 18400838]

15. Panepinto JA, Pajewski NM, Foerster LM, Hoffmann RG. The performance of the PedsQL generic core scales in children with sickle cell disease. J Pediatr Hematol Oncol. 2008; 30:666-673. [PubMed: 18776758]

16. Varni JW, Burwinkle TM, Seid M, et al. The PedsQL 4.0 as a pediatric measure: Feasibility, reliability, and validity. Ambul Pediatr. 2003; 3:329-341. [PubMed: 14616041]

17. Varni JW, Burwinkle TM, Jacobs JR, et al. The PedsQL in type 1 and type 2 diabetes: Reliability and validity of the Pediatric Quality of Life Inventory Generic Core Scales and type 1 Diabetes Module. Diabetes Care. 2003; 26:631-637. [PubMed: 12610013]

18. Varni JW, Burwinkle TM, Katz ER, et al. The PedsQL in pediatric cancer: Reliability and validity of the Pediatric Quality of Life Inventory Generic Core Scales, Multidimensional Fatigue Scale, and Cancer Module. Cancer. 2002; 94:2090-2106. [PubMed: 11932914]

19. Varni JW, Burwinkle TM, Rapoff MA, et al. The PedsQL in pediatric asthma: Reliability and validity of the Pediatric Quality of Life Inventory generic core scales and asthma module. J Behav Med. 2004; 27:297-318. [PubMed: 15259457]

20. Varni JW, Burwinkle TM, Berrin SJ, et al. The PedsQL in pediatric cerebral palsy: Reliability, validity, and sensitivity of the Generic Core Scales and Cerebral Palsy Module. Dev Med Child Neurol. 2006; 48:442-449. [PubMed: 16700934]

21. SAS/STAT® (for Windows) [computer program]. Version 9.1. Cary, NC: SAS Institute Inc.; 2003.

22. Cronbach LJ. Coefficient alpha and internal structure of tests. Psychometrika. 1951; 16:297-334.

23. Hatcher, L. A step-by-step approach to using the SAS system for factor analysis and structural equation modeling. Cary, NC: SAS Publishing; 1994. p. 712

24. Platt OS, Thorington BD, Brambilla DJ, et al. Pain in sickle cell disease. Rates and risk factors. N Engl J Med. 1991; 325:11-16. [PubMed: 1710777]

25. Gill FM, Sleeper LA, Weiner SJ, et al. Clinical events in the first decade in a cohort of infants with sickle cell disease. Blood. 1995; 86:776-783. [PubMed: 7606007]

26. Panepinto JA, Brousseau DC, Hillery CA, Scott JP. Variation in hospitalizations and hospital length of stay in children with vaso-occlusive crises in sickle cell disease. Pediatr Blood Cancer. 2005; 44:182-186. [PubMed: 15390359]

27. King A, Herron S, McKinstry R, Bacak S, Armstrong M, White D, DeBaun M. A multidisciplinary health care team's efforts to improve educational attainment in children with sickle-cell anemia and cerebral infarcts. J Sch Health. 2006; 76:33-37. [PubMed: 16457683]

28. Schatz J. Brief Report: Academic attainment in children with sickle cell disease. J Pediatr Psychol. 2004; 29:627-633. [PubMed: 15491985] 


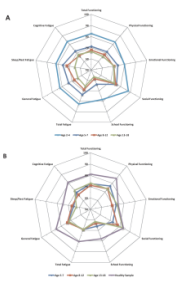

Figure 1.

(A) Parent-proxy reported Peds QL ${ }^{\mathrm{TM}}$ generic core and fatigue scale mean scores for age groups: 2-4, 5-7, 8-12, 13-18 years. (B) Child-reported Peds QL ${ }^{\mathrm{TM}}$ generic core and fatigue scale mean scores for age groups: 5-7, 8-12, 13-18 years, and healthy children [16]. 


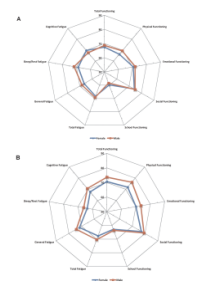

Figure 2.

Parent-proxy reported (A) and child-reported (B) Peds QL TM generic core and fatigue scale mean scores for hemoglobinopathy groups: $\mathrm{SS} / \mathrm{S} \beta^{0}$ thalassemia, $\mathrm{SC} / \mathrm{S} \beta^{+}$thalassemia. 


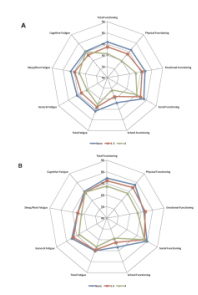

Figure 3.

Parent-proxy reported (A) and child-reported (B) Peds $\mathrm{QL}^{\mathrm{TM}}$ generic core and fatigue scale means scores for hospitalization frequency groups: none, $1-3, \geq 4$ in previous 2 years. 
Table I

Sample Characteristics

\begin{tabular}{|c|c|c|}
\hline \multirow[b]{3}{*}{ Age } & \multicolumn{2}{|c|}{ Age Group } \\
\hline & $\begin{array}{c}2-4 \\
(N=379)\end{array}$ & $\begin{array}{c}5-18 \\
(\mathrm{~N}=1393)\end{array}$ \\
\hline & & \\
\hline $\mathrm{n}$ & 379 & 1393 \\
\hline Mean (SD) & $3.4(0.87)$ & $11.4(3.78)$ \\
\hline \multicolumn{3}{|l|}{ Gender (n [\%]) } \\
\hline Female & $186(49.1)$ & $639(45.9)$ \\
\hline Male & $193(50.9)$ & $754(54.1)$ \\
\hline \multicolumn{3}{|l|}{ Phenotype (n [\%]) } \\
\hline SC-SB+ & $120(31.7)$ & $442(31.7)$ \\
\hline SS-SB0 & $259(68.3)$ & $951(68.3)$ \\
\hline \multicolumn{3}{|l|}{ Ethnicity (n [\%]) } \\
\hline Hispanic or Latino & $19(5.0)$ & $61(4.4)$ \\
\hline Not Hispanic or Latino & $360(95.0)$ & $1330(95.5)$ \\
\hline \multicolumn{3}{|l|}{ Race (n [\%]) } \\
\hline Black / Black Biracial & $356(93.9)$ & $1330(95.5)$ \\
\hline Not Black / Black Biracial & $23(6.1)$ & $63(4.5)$ \\
\hline \multicolumn{3}{|c|}{ Complications or conditions (n [\%]) } \\
\hline Priapism & $7 / 193(3.6)$ & 105/754 (13.9) \\
\hline Avascular necrosis & $0(0)$ & $62(4.5)$ \\
\hline Asthma & $49(12.9)$ & $342(24.6)$ \\
\hline Transfusion & $90(23.7)$ & $443(31.8)$ \\
\hline \multicolumn{3}{|l|}{ Hemoglobin (g/dL) } \\
\hline $\mathrm{n}$ & 350 & 1156 \\
\hline Mean (SD) & $9.4(1.60)$ & $9.5(1.74)$ \\
\hline Median & 9.2 & 9.4 \\
\hline (Min, Max) & $(5.1,14.3)$ & $(5.2,15.7)$ \\
\hline \multicolumn{3}{|c|}{ Acute care visits for pain in past year (visits) } \\
\hline $\mathrm{n}$ & 378 & 1384 \\
\hline Mean (SD) & $1.5(3.06)$ & $2.6(4.90)$ \\
\hline Median & 0 & 1 \\
\hline (Min, Max) & $(0,40)$ & $(0,50)$ \\
\hline \multicolumn{3}{|c|}{ School missed in previous year (days) } \\
\hline $\mathrm{n}$ & 377 & 1384 \\
\hline Mean (SD) & $2.4(7.94)$ & $13.1(21.90)$ \\
\hline Median & 0 & 7 \\
\hline (Min, Max) & $(0,90)$ & $(0,300)$ \\
\hline \multicolumn{3}{|c|}{ Caregiver, work missed in previous year (days) } \\
\hline $\mathrm{n}$ & 378 & 1385 \\
\hline
\end{tabular}

Pediatr Blood Cancer. Author manuscript; available in PMC 2011 September 1. 


\begin{tabular}{lcc}
\hline & \multicolumn{2}{c}{ Age Group } \\
& $\mathbf{2 - 4}$ & $\mathbf{5 - 1 8}$ \\
& $(\mathbf{N}=\mathbf{3 7 9})$ & $(\mathbf{N}=\mathbf{1 3 9 3})$ \\
\cline { 2 - 3 } Mean (SD) & $5.2(10.44)$ & $7.9(26.88)$ \\
Median & 0 & 2 \\
(Min, Max) & $(0,90)$ & $(0,365)$ \\
\hline
\end{tabular}




\section{Table IV}

Regression Coefficient Estimates for the Relationship between QOL Scores and Frequency of Missed School/ Work

\begin{tabular}{|c|c|c|c|c|}
\hline \multirow[b]{2}{*}{ QOL Scales } & \multicolumn{2}{|c|}{$\begin{array}{l}\text { \# of Days Children } \\
\text { Missed School }\end{array}$} & \multicolumn{2}{|c|}{$\begin{array}{c}\text { \# of Days Caregiver } \\
\text { Missed Work }\end{array}$} \\
\hline & $\begin{array}{c}\text { Regression } \\
\text { Coefficient (SE) }\end{array}$ & p-value & $\begin{array}{c}\text { Regression } \\
\text { Coefficient (SE) }\end{array}$ & p-value \\
\hline \multicolumn{5}{|l|}{ Parent-report } \\
\hline Total Functioning & $-0.21(0.02)$ & $<.001$ & $-0.09(0.02)$ & $<.001$ \\
\hline Physical Functioning & $-0.19(0.03)$ & $<.001$ & $-0.08(0.02)$ & $<.001$ \\
\hline Emotional Functioning & $-0.21(0.03)$ & $<.001$ & $-0.10(0.02)$ & $<.001$ \\
\hline Social Functioning & $-0.18(0.03)$ & $<.001$ & $-0.09(0.02)$ & $<.001$ \\
\hline School Functioning & $-0.25(0.03)$ & $<.001$ & $-0.09(0.02)$ & $<.001$ \\
\hline Total Fatigue & $-0.20(0.02)$ & $<.001$ & $-0.10(0.02)$ & $<.001$ \\
\hline General Fatigue & $-0.23(0.03)$ & $<.001$ & $-0.12(0.02)$ & $<.001$ \\
\hline Sleep/Rest Fatigue & $-0.23(0.03)$ & $<.001$ & $-0.11(0.02)$ & $<.001$ \\
\hline Cognitive Fatigue & $-0.13(0.03)$ & $<.001$ & $-0.08(0.03)$ & 0.002 \\
\hline \multicolumn{5}{|l|}{ Child-report } \\
\hline Total Functioning & $-0.13(0.02)$ & $<.001$ & $-0.09(0.02)$ & $<.001$ \\
\hline Physical Functioning & $-0.13(0.02)$ & $<.001$ & $-0.08(0.02)$ & $<.001$ \\
\hline Emotional Functioning & $-0.11(0.03)$ & $<.001$ & $-0.08(0.02)$ & $<.001$ \\
\hline Social Functioning & $-0.10(0.03)$ & $<.001$ & $-0.07(0.02)$ & $<.001$ \\
\hline School Functioning & $-0.19(0.02)$ & $<.001$ & $-0.12(0.02)$ & $<.001$ \\
\hline Total Fatigue & $-0.10(0.02)$ & $<.001$ & $-0.07(0.02)$ & $<.001$ \\
\hline General Fatigue & $-0.14(0.02)$ & $<.001$ & $-0.09(0.02)$ & $<.001$ \\
\hline Sleep/Rest Fatigue & $-0.12(0.03)$ & $<.001$ & $-0.08(0.02)$ & $<.001$ \\
\hline Cognitive Fatigue & $-0.05(0.03)$ & 0.102 & $-0.06(0.02)$ & 0.015 \\
\hline
\end{tabular}

Separate linear regression models including either days missed by children or by caregivers, controlling for age, gender, and hemoglobinopathy type 